\title{
Labor Markets and National Culture: Salary Determination in Japanese Baseball
}

\author{
Michael A. Leeds ${ }^{a}$, Sumi Sakata ${ }^{b}$ and Peter von Allmen ${ }^{c}$ \\ ${ }^{a}$ Department of Economics, Temple University, Philadelphia, PA 19122, USA. \\ ${ }^{\mathrm{b}}$ Temple University School of Law, Tokyo, Campus, Mita Hall, 4-1-27 Mita, Minato-ku, \\ Tokyo 108-0073, JAPAN. \\ ${ }^{\mathrm{c}}$ Department of Economics, Skidmore College, Harder Hall, Saratoga Springs, NY 12866, USA.
}

We analyze the determinants of salaries for players in Nippon Professional Baseball (NPB) using performance data from 2004 to 2006 and compensation data from 2005 to 2007. We find that salaries in NPB are determined by different factors than those that drive salaries in Major League Baseball (MLB). We also find that experience plays a significant role in salary determination, which suggests that the Japanese emphasis on seniority still holds in NPB. Finally, we show that free agency has relatively little impact on salaries in NPB, which suggests that players in NPB are subject to greater monopsony power than players in MLB.

Eastern Economic Journal (2012) 38, 479-494. doi:10.1057/eej.2011.25;

published online 5 December 2011

Keywords: baseball; Japan; salaries; seniority; monoposony

JEL: L83; J31

\section{INTRODUCTION}

The pay of professional baseball players is perhaps the most frequently studied topic in the economics of sports. Existing studies have largely focused on the impact of monopsony power, unions, discrimination, and free agency on the salaries of Major League Baseball (MLB) players in North America. Although Japan has been home to professional baseball for about 75 years, surprisingly few studies have been devoted to the internal workings of Nippon Professional Baseball (NPB) or to the determination of salaries among Japanese baseball players. Notable exceptions include Ohkusa and Ohtake [1996], who test whether managers affect the productivity of their players; Ohkusa [1999], who tests whether incentives and compensation change as players age; Dworkin and Jelf [1996], who describe labor relations in Japanese baseball; and Nakazato and Ramseyer [2007], who examine the impact of free agency. The latter three studies are relevant for this paper, and we shall discuss them in greater detail later.

The central goal of this paper is to identify the primary determinants of player salaries in NPB. We use a data set constructed from a variety of sources to investigate several features of salary determination among "position players" (i.e., non-pitchers) in NPB, including the returns to performance and experience. Comparing our results to those for MLB allows us to determine whether players are rewarded for the same performance measures across the two leagues. In addition, we test whether free agency has had a similar effect on salaries in MLB and NPB. It is well known that free agency has dramatically increased player compensation in MLB. Prior to becoming eligible for free agency, MLB players are often paid salaries far below their marginal revenue products (MRPs). Whether this same pay disparity is true in NPB is an open question. 
We are particularly interested in cultural differences that might drive differences in player salaries in the MLB and NPB. Experience plays a central role in most empirical studies of worker compensation because it serves as a proxy for the acquisition of human capital. The myriad performance measures in professional sports provide direct measures of human capital, typically making experience unnecessary. Because Japan provides a cultural setting in which experience could have an independent effect on pay, we test whether experience affects pay in NPB even when performance is held constant.

Finally, we investigate whether salary disparities stem from unique institutional features of NPB. We test whether players in NPB's Central League earn more than otherwise equivalent players in the Pacific League. We also test whether players for the Yomiuri Giants, a team with history, stature, and financial wherewithal analogous to MLB's New York Yankees, make more than other players. In a separate equation we also test more extensively for the presence of team-specific effects.

Our results indicate that, in general, players in NPB are compensated based on their ability to produce runs and experience independent of productivity. While the ability to hit and hit for power are important, there is some evidence that "small ball" tactics, specifically stolen bases and walks, are also important. We also find that, while achieving free agent status significantly increases salaries in NPB, the impact is smaller than in MLB and is similar to the returns to achieving arbitrationeligible status in MLB. Free agent status has a more complex meaning in Japan, as players can sell their services to other NPB teams before they have the opportunity to sign with MLB teams. We find that international free agency affects pay, while domestic free agency does not. Finally, we find some evidence that Central League teams pay their players less than Pacific League teams do.

\section{BASEBALL IN JAPAN}

One of the most striking features of Japanese baseball is the integration of teams with the companies that own them. Such integration is neither new nor unique to Japan. Since the formation of the National League of Baseball Clubs in the US in 1876, team owners have tried to combine their baseball interests with outside corporate interests. The convergence of beer and baseball that took place when the Busch family purchased the Saint Louis Cardinals in 1953 was just an echo of saloonkeeper Chris von der Ahe's motives in purchasing the St. Louis Browns (later re-named the Cardinals) in 1882 [Seymour 1960; Helyar 1994].

In Japan, teams have taken integration to a much higher level. Rather than being owned by individuals with related business interests, most Japanese teams are subdivisions of larger corporate entities. ${ }^{1}$ While MLB teams have traditionally identified with the city or state in which they play, NBP teams are linked to their parent companies. Thus, while all MLB fans know where the Detroit Tigers or the Colorado Rockies play, all NPB fans know that the Nippon Ham Fighters are owned by the Nippon Ham Group, a subsidiary of Nippon Meat Packers, Inc.

Sometimes baseball and larger corporate interests are directly linked. For example, the Hanshin Tigers were created by the Hanshin Electric Railway Company (now Hankyu Hanshin Holdings, Inc.) in order to create more business for a railway line from Osaka to a nearby baseball stadium and entertainment complex [Guttmann and Thompson 2001.] 
Like MLB, NPB is divided into two leagues, the Central League and the Pacific League. The Pacific League is generally considered the financially weaker league [Fisher 2007]. Leeds and Sakata [forthcoming] show that, all else equal, a Central League team draws about 10,000 more fans to a home game than a Pacific League team does.

The Yomiuri Giants play a unique role in NPB. They were formed in 1935 by Matsutaro Shoriki, the owner of the Yomiuri Shimbun, Japan's leading newspaper. A year earlier, the paper had sponsored a highly popular tour of MLB All Stars. Seeking to capitalize on the interest generated by the tour, Shoriki turned the Japanese players he had recruited to play the touring Americans into a stable professional team. For decades, the Yomiuri Giants have been akin to a combination of the New York Yankees and Notre Dame, dominating the public eye and building a nationwide fan base. The team's success is largely due to the Yomiuri Shimbun's use of its wide circulation (and, in recent years, its wider media holdings) to publicize the team.

Little financial information regarding NPB franchises is available to the general public, but it is widely accepted that only a handful of teams make a profit. Most parent companies regard their teams as a marketing expense. Moreover, unlike MLB, NPB has no mechanism for the more profitable teams to share revenue with the less profitable teams. The only concession to group activity is the 80 million yen (about \$820,000 in April 2009) each team must pay to the commissioner's office. ${ }^{2}$

The labor market in NPB differs from that of MLB in many ways - some formal, some informal or cultural. NPB players are more restricted in how and when they can move, and NPB teams are limited in how much they can bid for players on other teams. These limits reduce competition for individual talent and give teams far more monopsony power than exists in MLB.

Each NPB team has an active roster of 28 players, including up to four players who are not Japanese citizens. ${ }^{3}$ No more than three of the four foreigners can be pitchers and no more than three can be position players. Unlike MLB players, NPB players, especially younger players, typically have 1-year contracts. Signing and performance-related bonuses represent a small fraction of total pay (usually less than 10 percent). The minimum annual salary for a player is 4.4 million yen, although a player may also receive up to $1 / 150$ of the difference between his annual salary and 15 million yen for each day he is on a team's active roster. ${ }^{4}$

While the game of baseball in Japan increasingly resembles its North American cousin [Guttmann and Thompson 2001], key elements of the game remain distinctly Japanese. In particular, the Japanese desire for $w a$, or harmony, still takes precedence over striving for individual gain. ${ }^{5}$ Whiting [1977] claims that players contribute to the team's $w a$ by following Japanese baseball's samurai code. The code has nothing to do with the mechanics of hitting or fielding. Instead, it emphasizes basic principles - such as hard work, commitment to the team rather than to individual goals, and proper decorum - that would make baseball players exemplars to the population at large. Whiting's code helps to explain why the Japan Players Association has been far less aggressive than the Major League Baseball Players Association. ${ }^{6}$

The lack of a strong union and the social disapproval of individualism are two major reasons why NPB payrolls are smaller than those of MLB teams. The median 2009 payroll in NPB was \$26.4 million, almost exactly one-third the median payroll in MLB. Table 1 shows that the Yomiuri Giants and the Hanshin Tigers had by far the largest payrolls in the league, more than twice those of the Rakuten Golden 
Table 1 Team payrolls in $\mathrm{NPB}^{\mathrm{a}}$

\begin{tabular}{ll}
\hline Team & Payroll \\
\hline Central League & \\
Chunichi Dragons & $\$ 30.02$ \\
Hanshin Tigers & $\$ 40.49$ \\
Hiroshima Carp & $\$ 17.71$ \\
Yakult Swallows & $\$ 23.77$ \\
Yokohama Bay Stars & $\$ 23.03$ \\
Yomiuri Giants & $\$ 45.30$ \\
& \\
Pacific League & \\
Lotte Marines & $\$ 27.67$ \\
Nippon Ham Fighters & $\$ 24.97$ \\
Orix Buffaloes & $\$ 26.04$ \\
Rakuten Golden Eagles & $\$ 20.74$ \\
Seibu Lions & $\$ 26.75$ \\
Soft Bank Hawks & $\$ 34.11$ \\
\hline
\end{tabular}

${ }^{\mathrm{a}}$ In millions of US\$.

Source: "Yomiuri Giants Top 2009 NPB Team Payrolls," Baseballworld.com, online at http:// baseballdeworld.com/2009/04/29/yomiuri-giants-top-2009-npb-team-payrolls/, April 29, 2009.

Eagles or the Hiroshima Carp. However, in absolute terms, the Giants' payroll of about $\$ 45$ million is lower than almost all MLB teams.

NPB players have enjoyed free agency since 1993, but they did not win it through the courts (as in the NFL) or through skillful maneuvering by the union (as in MLB). Instead, free agency was pushed through by the Yomiuri Giants, who saw it as a quick way to restock a depleted roster [Whiting 2004]. Moreover, NPB's free agency is far more limited than MLB's. Players can become free agents only after having played for 9 years (as opposed to six for MLB), and players' salaries cannot rise by more than 50 percent when they sign a free agent contract unless the team receives an exemption from the league commissioner. Perhaps because of these limits on bargaining power, only 7 of 83 eligible players filed for free agency after the 2008 season ["2010 Free Agents Etc."].

NPB's best players gained greater access to free agency after they began moving to MLB teams in the 1990s. For the years in our sample, Japanese-born players were eligible for domestic free agency after spending 8 years in the NPB and were eligible to sign with teams in other countries (such as MLB teams) after 9 years. ${ }^{7}$

Salary arbitration, which grants MLB players some market power before reaching free agency, provides little relief in NPB. Although the NPB bylaws permit players to submit salary disputes to binding arbitration, the composition of the arbitration panel has biased the results. The panel has been comprised of the NPB commissioner and the presidents of the Central and Pacific Leagues. Further, a player in Japan must represent himself in front of the panel and cannot rely on any representative to argue his case. If a player is unhappy with the result, his only option is to retire from the NPB. If a retired player wishes to return to the sport, he must gain the approval of his old team before entering into a contract with a new team [Dworkin and Jelf 1996]. As of 2009, only six players had submitted their disputes to the panel. Not surprisingly, the panel decided in favor of management in four of the cases, while the other two players received only small increases over the salaries set by their teams. ${ }^{8}$ 
Table 22009 attendance by team

\begin{tabular}{lc}
\hline Team & Average attendance \\
\hline Central League & \\
Chunichi Dragons & 31,922 \\
Hanshin Tigers & 41,765 \\
Hiroshima Carp & 26,015 \\
Yakult Swallows & 18,505 \\
Yokohama Bay Stars & 17,319 \\
Yomiuri Giants & 40,755 \\
& \\
Pacific League & \\
Lotte Marines & 20,350 \\
Nippon Ham Fighters & 27,699 \\
Orix Buffaloes & 17,860 \\
Rakuten Golden Eagles & 16,711 \\
Seibu Lions & 21,042 \\
Soft Bank Hawks & 31,194 \\
\hline
\end{tabular}

Japan's success on the world stage - it has won both World Baseball Championship tournaments - and the success of top Japanese players in MLB strongly suggest that the best Japanese players are as skilled as those in the US and Latin America. Attendance data indicate that Japanese fans share the same level of passion for the sport as their American counterparts. Table 2 shows the average per game attendance for all 12 NPB teams in 2009. Using the numbers from Table 2, the median NPB team drew about 23,500 fans, which is comparable to MLB's median daily attendance of 28,750 and is greater than the average attendance of nine MLB teams. The more popular Central League draws as many fans as MLB on average. The average attendance for NPB's two most popular teams, the Hanshin Tigers and Yomiuri Giants, would rank fourth and fifth in MLB for 2009. Moreover, ticket prices in Japan are roughly comparable to all but the most expensive MLB ballparks (such as New York and Boston).

The big disparities between MLB and NPB teams come in media and venue revenue. For example, in 2009, the Lotte Marines, a team located in the Tokyo metropolitan area, received only $\$ 1,500$ per game for their TV rights [Whiting 2010]. Even the mighty Yomiuri Giants broadcast fewer games and enjoy far lower ratings than they did in the early 2000s [Whiting 2004]. NPB teams also receive less venue revenue, as they do not receive the subsidies from local governments that MLB teams receive. ${ }^{9}$

\section{PREVIOUS STUDIES OF SALARY DETERMINATION IN MLB AND NPB}

Studies of salary determination in baseball date back to Rottenberg's [1956] analysis of the monopsony power wielded by owners as a result of MLB's reserve clause. The most notable studies of the baseball labor market since then - Scully [1974], Zimbalist [1992a, b], Krautmann [1999], and Krautmann et al. [2000] - have all used empirical models designed to compare a player's salary with his MRP.

Scully [1974] and Zimbalist [1992a, 1992b] take the same basic approach. Both use a two-step process. In the first step, they estimate how individual performance 
affects team performance, as measured by winning percentage. In the second step, they estimate how the team's winning percentage affects its revenue. This allows them to simulate an individual player's contribution to team revenue, his MRP. The main difference between the two models is that Scully looks at individual performance, while Zimbalist uses a player's performance relative to a possible replacement player.

Rather than imputing a player's MRP, Krautmann directly estimates the determinants of salary for free agents. Because such players sell their services on a competitive market, Krautmann assumes that they are paid their MRP:

$$
S_{i t}=M R P_{i t}=\alpha+\beta P_{i, t-1}+\sum_{j=1}^{K} \gamma_{j} X_{i j t}+\varepsilon_{i t}
$$

Player $i$ 's salary in year $t$, which is by assumption equal to his MRP, depends on a measure of the player's productivity in the previous year $\left(P_{i, t-1}\right)$ and $K$ control variables $\left(X_{i j t}\right)$, such as the player's position. (For a summary of the Krautmann approach, see Krautmann et al. 2009.) He then uses the resulting equation to simulate the MRP of players who are still bound to their teams. Subtracting the salaries of these bound players from their estimated MRPs yields the impact of the teams' monoposony power.

All of the above models omit experience as a determinant of salary, except, in the case of Zimbalist and Krautmann, as a determinant of the player's access to free agency. This reflects the implicit assumption that experience has no independent effect on a player's contribution to team performance. A study by Blass [1992] provides a contrary view, finding an independent contribution of experience. Blass estimates the equation

$$
W=\delta_{1} X+\delta_{2} V A L+e
$$

where (using Blass's notation) $W$ is the player's salary, $X$ is his years of experience, and $V A L$ is his value to the team, which Blass postulates is a function of a player's plate appearances, the runs his team needs to win one more game, the runs and outs the player generates per plate appearance, and the marginal revenue of one more win to the player's team. Marginal revenue, in turn, is postulated as a function of attendance and broadcast revenue. Blass estimates these two revenue streams as functions of their lagged values, characteristics of the team's metropolitan area, ticket prices, and measures of the team's recent success. Blass estimates equation (2) and finds that experience has a positive impact on the pay of all players except those with more than 6 years of experience, that is, those who are eligible for free agency. As noted above, perhaps because $V A L$ is so idiosyncratic, Blass's findings have not had much impact on later studies, which typically omit experience.

While MLB's labor market has been the subject of many studies, NPB's labor market has received little attention in the English-language literature. The only relevant studies of salary determination are Ohkusa [1999] and Nakazato and Ramseyer [2007]. Interestingly, both papers cite an independent role for experience, though their views of that role differ significantly.

Ohkusa is less concerned with salary determination per se than with what he calls "the career concern hypothesis," the notion that employees require different incentives as they approach retirement. Ohkusa hypothesizes that younger players do not require explicit incentives, such as higher pay, because they are worried about the future course of their careers. As players approach retirement, they are less concerned about future employment and require more explicit incentives. Ohkusa 
tests this hypothesis with the equation

$$
\ln \left(w_{i t}\right)=\alpha_{i}+\sum_{\tau=1}^{10}\left\{\beta_{\tau} \ln \left(X_{i t}\right)+\gamma_{\tau}\right\} Z_{i, t, \tau}+\varepsilon_{i t}
$$

where $w_{i t}$ is the salary of player $i$ in year $t, X_{i t}$ is a measure of performance (Ohkusa uses slugging percentage), $Z_{i, t, t}$ reflects the likelihood that player $i$ will retire in year $t$, and $\tau$ is the number of years until player $i$ retires. (We have added the error term to Ohkusa's equation.) Ohkusa estimates (3) and finds that explicit incentives play a greater role for more experienced players. This translates into a positive impact of experience on salaries.

Nakazato and Ramseyer [2007] study the impact of free agency, performance, and nationality on pay. As a result, their empirical specification, shown in equation (4), is closer to the MLB studies than Ohkusa's.

$$
\ln \left(S_{i, 04}\right)=\alpha+\sum_{j=1}^{K} \beta_{j} P_{i, j, 03}+\gamma Y_{04}+\sum_{j=1}^{L} \delta_{j} X_{i j}+\varepsilon_{i t}
$$

The dependent variable in equation (4), $S_{i, 04}$, is player $i$ 's total compensation in 2004, which includes his salary, bonus payments, and outside income from product endorsements. $P_{i, j, 03}$, is a vector of performance measures. These performance measures differ from those used in most studies of salary determination in MLB, as they consist of at bats and a dummy variable that indicates a high batting average relative to slugging percentage. $Y_{04}$, is a player's years of experience in 2004. Finally, $X_{i j}$, consists of a series of dummy variables that indicate whether a player is a free agent, is from the United States, and is African American. In a variant of the above, they also include variables that interact free agency with the other variables. They run OLS regressions using all players with any NPB experience in 2003 who were on an NPB roster in 2004.

Although their measures of performance are not the same as those used in recent studies of MLB, Nakazato and Ramseyer find that, while NPB players receive far lower salaries than MLB players, the determinants of salary in NPB are the same as for MLB. They also conclude that American players in NPB receive a salary premium and that there is no difference in the salaries paid to white and African American players. They find that experience has a complex impact on salaries. In particular, players receive large bonuses when they first sign with a team but very low salaries afterwards. Once the team has made back its investment (which they infer occurs after about 6 years of play in NPB), the player is then compensated at the same level as a free agent. According to Nakazato and Ramseyer, most players' careers last only 2-3 years, so teams appear not to make back their initial investment.

\section{EMPIRICAL MODEL AND DATA}

The structure of our empirical model, shown in equation (5), closely resembles that of Nakazato and Ramseyer [2007], but its components are very different.

$$
\ln \left(S_{i, t}\right)=\alpha+\sum_{j=1}^{K} \beta_{j} P_{i, j, t-1}+\gamma Y_{i t}+\sum_{j=1}^{L} \delta_{j} X_{i j t}+\varepsilon_{i t}
$$


Unlike Equation (4), Equation (5) uses the natural logarithm players' salaries as the dependent variable rather than total earnings from all sources. The salary figures are adjusted for inflation, though inflation was near zero for the years in the sample.

$P$ is a vector of performance measures. In our model, we employ a more comprehensive set of such measures than Nakazato and Ramseyer: OPS (described below), strikeouts per game, stolen bases per game, and bases on balls (walks) per game. "OPS" is an acronym for "On-base percentage Plus Slugging percentage." On base percentage is the probability that a player reaches base for a given plate appearance. It equals a fraction with the sum of hits, bases on balls, and times a player was hit by a pitch in the numerator and the sum of at bats, bases on balls, number of times hit by pitch and number of sacrifice flies in the denominator. ${ }^{10}$ "Slugging percentage" differs from on-base percentage in that it gives greater weight to extra-base hits such as home runs than it does to singles. Slugging percentage is the total number of bases per at-bat. It is a fraction with the sum of the number of singles, two times the number of doubles, three times the number of triples, and four times the number of home runs in the numerator and the number of at-bats in the denominator. The OPS thus combines a measure of a player's ability to get on base with his ability to hit for power.

A simple set of means shows the importance of OPS in determining salary. The average salary of a player in our sample with an OPS greater than 0.900 , which is typically regarded as truly outstanding was the equivalent of about $\$ 2.5$ million. ${ }^{11}$ In contrast, the average salary of a player with an OPS less than 0.700 , which is below average, was only about $\$ 500,000$.

Other performance variables are calculated on a per game basis because, over this time period, Central League teams had a longer season than did Pacific League teams. Normalizing by the number of games eliminates this source of variation.

Like Ohkusa [1999] and Nakazato and Ramseyer [2007], we include experience $\left(Y_{i t}\right)$ in our model. However, we have a different reason for doing so. Unlike Ohkusa, we do not believe that the impact of experience stems from an incentive mechanism that would hold equally well in MLB, and, unlike Nakazato and Ramseyer, we do not believe that the impact of experience ends by the time a player becomes eligible for free agency. We think that experience affects salaries in NPB for a distinctly Japanese reason. Because of its concern for wa, baseball in Japan (like much of the Japanese economy as a whole) has a long tradition of reward based on seniority. In the words of one former player:

In old Japan, the rookies had to do all the menial things, because they have the peer structure - the sempai-kohai (senior-junior) structure. ... The veterans would eat first, and then the younger players would be served. The same thing held true for the bath. The youngsters always took their baths after the veterans, so they always bathed in lukewarm water. [Fitts 2005, p. 61]

To the degree that the sempai-kohai system still holds in NPB, one would expect seniority to play a role in player compensation. This seniority system still applies to much of the Japanese economy, though there are indications that its role has diminished since the Japan's "lost decade" of the 1990s. (See Kwon 2004, for a particularly good summary of the issue.) We test the hypothesis that experience affects salaries in NPB by including linear and quadratic measures of a player's experience in the wage equation. Including the quadratic measure allows us to test 
for the presence of increasing or decreasing returns. In addition, if, as expected, there are decreasing returns to experience, we can use the estimates to compute an experience-earnings profile and determine the level of experience that maximizes a player's salary. The possibility of an internal maximum allows us to distinguish our study from Ohkusa [1999], whose model allows for no maximum, and from Nakazato and Ramseyer [2007], who see the impact of experience ending with free agency.

Our vector of control variables $\left(X_{i j t}\right)$ is also unique to this study. We include two sets of dummy variables. The first set captures a league effect to determine whether the Central League pays higher salaries than the Pacific League, given our measure of performance. It also captures whether the Yomiuri Giants, long regarded as NPB's version of the high-spending New York Yankees, spends more on players than other teams. The second set of control variables replaces the league dummy with a dummy variable for each team in NPB. (The Hanshin Tigers of the Central League are the default.) The dummy variables likely reflect the willingness or ability of teams to pay high salaries. While in theory they could capture differences in the dimensions of stadiums that affect a player's ability to hit, the dimensions of stadiums in NPB are remarkably uniform. ${ }^{12}$

Performance measures can change dramatically due to small changes in actual performance when players have few at bats. Therefore, we restrict our sample to players with at least $100 \mathrm{NPB}$ at bats in a season. Because this restriction significantly reduces the number of possible observations, we employ a panel with performance data for 2004-2006 and salary data for 2005-2007. The resulting data set contains 420 observations, 68 of which are for players who are eligible for free agency. This panel data set is unbalanced because some players ended their careers in either 2004 or 2005 (left truncation), others began their careers in either 2005 or 2006 (right truncation), and still others had careers that lasted only 1 or 2 years. To account for the possibility that the results from estimating this panel data set might be affected by players whose careers lasted only 1 or 2 years, we also estimated a balanced panel with players who played for all 3 years. As Table 3 shows, players in the balanced sample have higher salaries, generally perform better, and are more likely to be eligible for free agency than players in the unbalanced sample. We control for the impact of free agency by including a dummy variable that indicated whether the player was eligible for international free agency, meaning he could sign with a team outside of Japan.

Because a complete set of revenue figures for NPB teams is not available, we do not compare players' salaries with their MRPs. We take a simpler approach to wage determination than the MLB studies. Like Nakazato and Ramseyer, we include in our sample both free agents and players who are bound to their teams. We account for the greater bargaining power of free agents by including a dummy variable that equals one if a player is eligible for free agency.

A Hausman test revealed that the data were best estimated using a model with fixed player effects. Because we use a fixed-effects model, we cannot include timeinvariant variables in our estimation. As a result, we cannot determine the impact on salary of being foreign-born.

Productivity data for 2004-2006 are from Pro Yakyu Database [Westbay 2008]. Data on player characteristics (position and tenure) and salary are from the Japan Pro Baseball Fan Handbook and Media Guide, compiled annually by Wayne Graczyk [Graczyk 2005, 2006, 2007]. Salary is discounted to 2005 levels, though inflation was not a factor in this time period. 
i. Michael A. Leeds et al.

488

Salary Determination in Japanese Baseball

Table 3 Means and standard deviations of key variables

\begin{tabular}{|c|c|c|}
\hline Variable & Unbalanced sample & Balanced sample \\
\hline Salary & $\begin{array}{c}1,052,747 \\
(1,131,314)\end{array}$ & $\begin{array}{c}1,372,865 \\
(1,216,555)\end{array}$ \\
\hline OPS & $\begin{array}{c}0.748 \\
(0.129)\end{array}$ & $\begin{array}{c}0.772 \\
(0.128)\end{array}$ \\
\hline Strikeouts per game & $\begin{array}{c}0.588 \\
(0.199)\end{array}$ & $\begin{array}{c}0.612 \\
(0.204)\end{array}$ \\
\hline Walks per game & $\begin{array}{c}0.085 \\
(0.036)\end{array}$ & $\begin{array}{c}0.303 \\
(0.136)\end{array}$ \\
\hline Stolen bases per game & $\begin{array}{c}0.014 \\
(0.019)\end{array}$ & $\begin{array}{c}0.043 \\
(0.068)\end{array}$ \\
\hline Years of experience & $\begin{array}{c}9.569 \\
(5.095)\end{array}$ & $\begin{array}{c}9.900 \\
(4.625)\end{array}$ \\
\hline Eligible for free agency & $\begin{array}{c}0.031 \\
(0.173)\end{array}$ & $\begin{array}{c}0.046 \\
(0.210)\end{array}$ \\
\hline Played in Central League & $\begin{array}{c}0.452 \\
(0.498)\end{array}$ & $\begin{array}{c}0.538 \\
(0.500)\end{array}$ \\
\hline Played for Bay Stars & $\begin{array}{c}0.076 \\
(0.266)\end{array}$ & $\begin{array}{c}0.096 \\
(0.295)\end{array}$ \\
\hline Played for Carp & $\begin{array}{c}0.083 \\
(0.276)\end{array}$ & $\begin{array}{c}0.092 \\
(0.290)\end{array}$ \\
\hline Played for Dragons & $\begin{array}{c}0.069 \\
(0.254)\end{array}$ & $\begin{array}{c}0.096 \\
(0.295)\end{array}$ \\
\hline Played for Giants & $\begin{array}{c}0.069 \\
(0.254)\end{array}$ & $\begin{array}{c}0.085 \\
(0.279)\end{array}$ \\
\hline Played for Swallows & $\begin{array}{c}0.081 \\
(0.273)\end{array}$ & $\begin{array}{c}0.062 \\
(0.241)\end{array}$ \\
\hline Played for Tigers & $\begin{array}{c}0.071 \\
(0.258)\end{array}$ & $\begin{array}{c}0.104 \\
(0.306)\end{array}$ \\
\hline Played for Blue Wave & $\begin{array}{c}0.021 \\
(0.145)\end{array}$ & $\begin{array}{c}0.015 \\
(0.123)\end{array}$ \\
\hline Played for Buffaloes & $\begin{array}{c}0.081 \\
(0.273)\end{array}$ & $\begin{array}{c}0.077 \\
(0.267)\end{array}$ \\
\hline Played for Fighters & $\begin{array}{c}0.083 \\
(0.277)\end{array}$ & $\begin{array}{c}0.069 \\
(0.254)\end{array}$ \\
\hline Played for Golden Eagles & $\begin{array}{c}0.076 \\
(0.266)\end{array}$ & $\begin{array}{c}0.031 \\
(0.173)\end{array}$ \\
\hline Played for Hawks & $\begin{array}{c}0.081 \\
(0.273)\end{array}$ & $\begin{array}{c}0.069 \\
(0.254)\end{array}$ \\
\hline Played for Lions & $\begin{array}{c}0.107 \\
(0.310)\end{array}$ & $\begin{array}{c}0.088 \\
(0.284)\end{array}$ \\
\hline Played for Marines & $\begin{array}{c}0.093 \\
(0.291)\end{array}$ & $\begin{array}{c}0.104 \\
(0.306)\end{array}$ \\
\hline Number of observations & 420 & 260 \\
\hline
\end{tabular}

Standard deviations in parentheses.

\section{RESULTS}

Results of the estimation are shown in Tables 4 and 5. Table 4 shows the results for the unbalanced panel, and Table 5 shows the results for the balanced panel (in which players played all 3 years). The first column of each table uses league and Yomiuri Giant effects, while the second column uses the full set of individual team effects. The overall fit of the equations is very good given that we use cross sectional data, as 
Table 4 Determinants of salary using an unbalanced sample

\begin{tabular}{|c|c|c|}
\hline Variable & League indicator & Team indicators \\
\hline OPS & $\begin{array}{l}0.860 * * * \\
(3.24)\end{array}$ & $\begin{array}{l}1.021 * * * \\
(3.69)\end{array}$ \\
\hline Strikeouts per game & $\begin{array}{l}0.426^{* * *} \\
(2.27)\end{array}$ & $\begin{array}{l}0.322^{*} \\
(1.68)\end{array}$ \\
\hline Stolen bases per game & $\begin{array}{c}0.824 \\
(1.21)\end{array}$ & $\begin{array}{r}0.837 \\
(1.21)\end{array}$ \\
\hline Bases on balls per game & $\begin{array}{l}0.620 * * \\
(2.18)\end{array}$ & $\begin{array}{l}0.492^{*} \\
(1.70)\end{array}$ \\
\hline Years of experience & $\begin{array}{l}0.442 * * * \\
(9.02)\end{array}$ & $\begin{array}{l}0.446^{* * *} \\
(9.12)\end{array}$ \\
\hline Experience squared & $\begin{array}{l}-0.015^{* * *} \\
(6.91)\end{array}$ & $\begin{array}{l}-0.014 * * * \\
(6.81)\end{array}$ \\
\hline Eligible for free agency & $\begin{array}{l}0.201^{* *} \\
(2.00)\end{array}$ & $\begin{array}{l}0.210^{*} \\
(1.95)\end{array}$ \\
\hline Played in Central League & $\begin{array}{l}-0.336^{* *} \\
(2.07)\end{array}$ & - \\
\hline Played for Giants & $\begin{array}{c}0.194 \\
(1.06)\end{array}$ & $\begin{array}{c}0.369 \\
(1.54)\end{array}$ \\
\hline Played for Bay Stars & - & $\begin{array}{c}-0.358 \\
(1.31)\end{array}$ \\
\hline Played for Carp & - & $\begin{array}{c}0.283 \\
(0.96)\end{array}$ \\
\hline Played for Dragons & - & $\begin{array}{c}-0.371 \\
(1.07)\end{array}$ \\
\hline Played for Swallows & - & $\begin{array}{l}0.608^{*} \\
(1.88)\end{array}$ \\
\hline Played for Blue Wave & - & $\begin{array}{l}0.532 * * \\
(1.98)\end{array}$ \\
\hline Played for Buffaloes & - & $\begin{array}{l}0.583^{* *} \\
(2.37)\end{array}$ \\
\hline Played for Fighters & - & $\begin{array}{c}0.468 \\
(1.55)\end{array}$ \\
\hline Played for Golden Eagles & - & $\begin{array}{c}0.533^{*} \\
(1.89)\end{array}$ \\
\hline Played for Hawks & - & $\begin{array}{c}-0.042 \\
(0.15)\end{array}$ \\
\hline Played for Marines & - & $\begin{array}{l}0.501^{*} \\
(1.81)\end{array}$ \\
\hline Constant & $\begin{array}{r}5.375 \\
(16.65)\end{array}$ & $\begin{array}{l}4.763^{* * * *} \\
(12.13)\end{array}$ \\
\hline $\begin{array}{l}\text { Number of observations } \\
F \text {-statistic }\end{array}$ & $\begin{array}{r}420 \\
16.76\end{array}$ & $\begin{array}{r}420 \\
8.97\end{array}$ \\
\hline
\end{tabular}

$t$-statistics in parentheses; *significant at 10 percent level; **significant at 5 percent level; ***significant at 1 percent level.

seen by the $F$-statistics of the regressions. The results are very robust across specifications.

The coefficients of the performance variables largely accord with our expectations. OPS a strong positive impact on salary. While the point estimate is higher for the balanced sample than for the unbalanced sample, the difference is not statistically significant. There is some evidence to support the notion that Japanese teams prefer "small ball" over the power game that MLB rewards. This is seen in the 
Hichael A. Leeds et al.

490

Salary Determination in Japanese Baseball

Table 5 Determinants of salary using a balanced sample

\begin{tabular}{|c|c|c|}
\hline Variable & League indicator & Team indicators \\
\hline \multirow[t]{2}{*}{ OPS } & $1.164 * * *$ & $1.244 * * *$ \\
\hline & $(3.36)$ & $(3.66)$ \\
\hline \multirow[t]{2}{*}{ Strikeouts per game } & 0.327 & 0.188 \\
\hline & $(1.47)$ & $(0.83)$ \\
\hline \multirow[t]{2}{*}{ Stolen bases per game } & $1.422 *$ & 1.253 \\
\hline & $(1.74)$ & $(1.53)$ \\
\hline \multirow[t]{2}{*}{ Bases on balls per game } & 0.411 & 0.323 \\
\hline & $(1.29)$ & $(1.02)$ \\
\hline \multirow[t]{2}{*}{ Years of experience } & $0.462 * * *$ & $0.485^{* * *}$ \\
\hline & $(8.49)$ & $(9.05)$ \\
\hline \multirow[t]{2}{*}{ Experience squared } & $-0.014 * * *$ & $-0.014 * * *$ \\
\hline & $(5.39)$ & $(5.67)$ \\
\hline \multirow{2}{*}{ Eligible for free agency } & 0.153 & $0.193 *$ \\
\hline & $(1.43)$ & $(1.68)$ \\
\hline \multirow[t]{2}{*}{ Played in Central League } & 0.182 & - \\
\hline & $(0.85)$ & \\
\hline \multirow[t]{2}{*}{ Played for Giants } & 0.168 & $0.608^{* *}$ \\
\hline & $(0.79)$ & $(2.25)$ \\
\hline \multirow[t]{2}{*}{ Played for Bay Stars } & - & $-0.677^{*}$ \\
\hline & & $(1.92)$ \\
\hline \multirow[t]{2}{*}{ Played for Carp } & - & $0.749 * *$ \\
\hline & & $(2.23)$ \\
\hline \multirow{2}{*}{ Played for Dragons } & - & -0.447 \\
\hline & & $(1.30)$ \\
\hline \multirow[t]{2}{*}{ Played for Swallows } & - & $0.584^{*}$ \\
\hline & & $(1.77)$ \\
\hline \multirow[t]{2}{*}{ Played for Blue Wave } & - & 0.402 \\
\hline & & $(1.36)$ \\
\hline \multirow[t]{2}{*}{ Played for Buffaloes } & - & $0.491 *$ \\
\hline & & $(1.87)$ \\
\hline \multirow[t]{2}{*}{ Played for Fighters } & - & $0.757 * *$ \\
\hline & & $(2.41)$ \\
\hline \multirow[t]{2}{*}{ Played for Golden Eagles } & - & 0.189 \\
\hline & & $(0.52)$ \\
\hline \multirow[t]{2}{*}{ Played for Hawks } & - & 0.375 \\
\hline & & $(1.02)$ \\
\hline \multirow[t]{2}{*}{ Played for Marines } & - & $0.786^{* *}$ \\
\hline & & $(2.55)$ \\
\hline \multirow[t]{2}{*}{ Constant } & 5.029 & $4.461 * * *$ \\
\hline & $(10.87)$ & $(9.37)$ \\
\hline Number of observations & 260 & 260 \\
\hline$F$-statistic & 12.56 & 7.46 \\
\hline
\end{tabular}

$t$-statistics in parentheses; *significant at 10 percent level; **significant at 5 percent level; ***significant at 1 percent level.

positive impact of bases on balls in the unbalanced panel and of stolen bases in the balanced panel. The impact of bases on balls is particularly large. The emphasis on such skills is particularly interesting, as the slightly smaller size of Japanese ballparks would cause teams to stress home runs over walks and stolen bases.

The positive coefficient on strikeouts per game in Table 4 seems counterintuitive. The fact that the impact is insignificant in the balanced sample (Table 5) suggests that the result is driven by players who played less than 3 years with 100 or more at 
bats in time period covered. These players tended to be far less experienced (over 17 percent have less than 3 years of experience while only 1.9 percent of the balanced sample have this little experience). Moreover, the players in the imbalanced portion of the sample have relatively similar salaries but are very homogeneous in terms of their performance with respect to every metric except strikeouts per game. For example, players with less than 3 years of experience strike out over 0.6 times per game while players with more 9 years of experience strike out only 0.5 times per game, while their other performance metrics are virtually identical. Thus, holding all measures constant, strikeouts per game could reflect the investment that teams are making in younger players who strike out at a relatively higher rate.

While the Central League might dominate the Pacific League financially, this dominance does not translate into unusually high salaries for its players. In fact, in the unbalanced panel, the impact of playing in the Central League is negative, suggesting that the Pacific League overpays its players. The team dummies in the unbalanced panel reinforce this conclusion, as only one Central League team (the Swallows) has a significant positive coefficient, while three Pacific League teams (the Blue Wave, Buffaloes, and Golden Eagles) do. ${ }^{13}$ The balanced sample shows greater balance across the leagues, as the Central League dummy is insignificant and three teams from both the Central League (the Giants, Carp, and Swallows) and the Pacific League (the Buffaloes, Fighters, and Marines) overspend relative to the Tigers. One team, the Central League's Bay Stars, spend less than the Tigers, all else equal.

Experience has the expected positive, concave effect on salaries, though the degree of concavity is very low. The coefficients for the unbalanced sample suggest that the benefits to experience peak at 14.6 to 15.4 years. In the balanced sample, the peak comes even later, between 16.7 and 17.4 years. ${ }^{14}$ Thus, unlike Nakazato and Ramseyer [2007], we find that experience has an extended effect. Contrary to Ohkusa's [1999] "career concern" model, we find that experience has a decreasing marginal impact on salaries. The results suggest instead that the impact of experience reflects the continued sempai-kohai system in NPB. ${ }^{15}$

As expected, we find that international free agency increases wages by far less in NPB than it does in MLB. In a separate set of regressions (not shown here), we also included a dummy variable that indicated whether a player was eligible for domestic free agency (meaning he was free to sign with another NPB club but not with a team outside Japan) as well as variables interacting the eligibility for free agency with performance. Those results were no different from the results that appear in Tables 4 and 5, with the indicator for domestic free agency and the interaction terms being statistically insignificant. Thus, only the threat of leaving NPB altogether affects players' salaries. In addition, teams do not appear to weight performance any more heavily when a player is eligible for free agency.

Our estimates show that the impact of international free agency on salaries ranges from 18 to 20 percent in the unbalanced sample. In the balanced sample, the coefficient is significant only in the specification with team indicators and even then only at the 10 percent level. Similar to the results in the unbalanced sample, the coefficient here shows that achieving free agency increases salary by only 19 percent. $^{16}$

The 19 percent increase in salary attributable to free agency in NPB is roughly equivalent in percentage terms to the impact of free agency on MLB players found by Krautmann et al. [2009]. The difference is that Krautmann et al. find that salary arbitration has a large impact on MLB salaries, increasing players' compensation 
from 19 percent of their MRPs to about 86 percent on average. Because salary arbitration has had no impact on salaries in NPB, NPB players are subject to monopsony power far longer than MLB players are and that they do not benefit nearly as much as their counterparts in MLB from the relaxation of their employers' market power.

\section{CONCLUSION}

We find that the economic and cultural underpinnings of NPB differ significantly from those of MLB. These differences, in turn, affect both the degree to which human capital affects compensation and the specific forms of human capital that are rewarded.

Because free agent status is more difficult for players to attain and subject to more restrictions when they do attain it, NPB teams are more capable of restraining salaries than MLB teams. Our results indicate that the impact of free agency in Japan is roughly analogous in percentage terms to the impact of moving from salary arbitration to free agency in MLB. That said, the absolute change in pay is much smaller. Because previous studies have found that the largest boost in MLB salaries comes when the player becomes eligible for salary arbitration (after 3 years), Japanese players fall behind their American counterparts well before free agency has an effect. The lack of impartial arbitration has effectively extended the monopsony power of NPB teams to 9 years.

We also show that MLB and NPB reward different skills. Performance measures that play no role in any study of MLB of which we are aware have a statistically significant impact on salaries in NPB. These performance measures (bases on balls and stolen bases) are largely consistent with the "small ball" game tactics often associated with baseball in Japan. Anecdotal evidence has long maintained that NPB teams rely less on home runs than do MLB teams. Our study provides evidence that players in NPB are rewarded for advances on the base paths that lead to a run and not just for hitting a ball often or far.

Our results also indicate that experience plays an independent role in salary determination in Japan. In contrast, experience matters in MLB only because players need a specific level of experience to be eligible for salary arbitration or free agency. The impact of experience in NPB suggests that the Japanese desire for $w a$, as expressed by the rigid sempai-kohai system still plays a significant role in determining compensation in NPB.

Finally, we show that previous studies of salaries in NPB have neglected some key institutional factors. Unlike earlier estimates, our models control for the greater financial strength of the Central League and possible team-specific effects. Our finding thus suggests that prior studies suffer from omitted variable bias, which could explain some of the difference between their results and ours.

\section{Acknowledgements}

We thank Andrew Buck, Eva Marikova Leeds, the participants in a sports economics session at the 2009 Western Economic Association Annual Meetings and three anonymous referees for their valuable comments. Mayuko Yatsu and Alican Aytac provided important research assistance. 


\section{Notes}

1. The exception in NPB is the Hiroshima Carp, of which the Mazda Motor Corporation owns less than one-third.

2. Interview with Dr. Yusuke Suzumura, Secretary General of the Association of American Baseball Research and Visiting Academic Researcher at Hosei University, April 1, 2009.

3. Exceptions to the foreign player limitation exist for players who, prior to entering the NPB, either: (1) played baseball for at least three years in junior high, high school or junior college in Japan; (2) played at least 4 years of college baseball in Japan; (3) lived for 5 years or played baseball for at least 3 years in a team affiliated with the NPB; or (4) attained free agent status.

4. Interview with Dr. Yusuke Suzumura, April 1, 2009.

5. "In 2003 when Tokyo Giants infielder Mashiro Kawai set an all-time record for career sacrifice bunts with 514 , it was greeted with as much fanfare as if he had surpassed the home run record" [Whiting 2004, p. 51].

6. The JPA was not even officially recognized until 1981, while the MLBPA began operations in 1953.

7. Players signed to contracts after 2007 are eligible for domestic free agency after 7 years of experience.

8. Recent events show more promise for the players. NPB bylaws were amended in 2009 in an effort to create a more impartial arbitration panel. The panel now consists of the general counsel for the NPB commissioner, a former manager for the Hanshin Tigers, and a lawyer. In 2010, the revised panel awarded Hideaki Wakui a 33 million yen (roughly $\$ 400,000$ at 2009 exchange rates) increase over the salary set by the Seibu Lions [Sasaki 2011].

9. See Leeds and von Allmen [2010] for an account of how MLB teams can exploit monopsony power to drive up venue revenue.

10. Bases on balls, hit by pitch, and sacrifice do not count as at bats.

11. Fifty-one players in our sample had an OPS in excess of 0.900 . To lend some perspective, the highest career OPS in MLB belongs to Babe Ruth at 1.1638.

12. The distances down the rightfield and leftfield lines range from 308 feet to 330 feet, while the distance to the centerfield fence ranges from 390 feet to 400 feet.

13. The Blue Wave merged with the Buffaloes after the 2004 season, so they appear for only one year.

14. In the unbalanced sample, 90 players have at least 14 years of experience, while 26 players in the balanced sample have at least 17 years of experience.

15. We also wanted to include a player's age in the model, but we found that age and experience were highly correlated. As a result we did not include it.

16. Because all foreign players are effectively free agents, we also tried using a dummy variable equal to one for all Japanese eligible for free agency and all foreigners. The coefficient was never significant and the regressions are not shown here.

\section{References}

Blass, Asher C. 1992. Does the Baseball Market Contradict the Human Capital Model of Investment? The Review of Economics and Statistics, 74(May): 261-268.

Dworkin, James B., and Gregory S. Jelf. 1996. Labor Relations in Japanese Baseball, in Baseball Economics: Current Research, edited by John Fizel, Elizabeth Gustafson, and Lawrence Hadley Westport, CT: Praeger.

Fisher, Eric. 2007. Japan's Pacific League Pools Licensing Efforts, Street \& Smith's SportsBusiness Journal, http://www.sportsbusinessjournal.com/article/55288 (accessed May 28, 2007).

Fitts, Robert K. 2005. Remembering Japanese Baseball: An Oral History of the Game. Carbondale: Southern Illinois University Press.

Graczyk, Wayne 2005. Japan Pro Baseball Fan Handbook and Media Guide. Tokyo: Wayne Graczyk. . 2006. Japan Pro Baseball Fan Handbook and Media Guide. Tokyo: Wayne Graczyk. 2007. Japan Pro Baseball Fan Handbook and Media Guide. Tokyo: Wayne Graczyk.

Guttmann, Allen, and Lee Thompson. 2001. Japanese Sports: A History. Honolulu: University of Hawai'i Press.

Helyar, John. 1994. Lords of the Realm: The Real History of Baseball. New York: Ballantine Books.

Krautmann, Anthony. 1999. What's Wrong with Scully-Estimates of a Player's MRP? Economic Inquiry, 37(April): 369-381. 
Krautmann, Anthony C., Larry Hadley, and Elizabeth Gustafson. 2000. Who Pays for Minor League Training Costs? Contemporary Economic Policy, 18(January): 37-47.

Krautmann, Anthony C., Peter von Allmen, and David Berri. 2009. The Underpayment of Restricted Players in North American Sports Leagues. International Journal of Sport Finance, 4(August): 161-175.

Kwon, Hyeog-ki 2004. Japanese Employment Relations in Transition. Economic and Industrial Democracy, 25(August): 325-345.

Leeds, Michael A., and Sumi Sakata. Forthcoming. Take Me Out to the Yakyushiai: Determinants of Attendance at Nippon Professional Baseball Games. Journal of Sports Economics.

Leeds, Michael A., and Peter von Allmen. 2010. The Economics of Sports. Boston: Addison Wesley.

Nakazato, Minoru, and J. Mark Ramseyer. 2007. Bonuses and Biases in Japanese Baseball, John M. Olin Center for Law, Business, and Economics, Working Paper No. 589, June.

Ohkusa, Yasushi. 1999. Additional Evidence for the Career Concern Hypothesis with Uncertainty of the Retirement Period - The Case of Professional Baseball Players in Japan. Applied Economics, 31(November): 1481-1487.

Ohkusa, Yasushi, and Fumio Ohtake. 1996. The Relationship between Supervisor and Workers — The Case of Professional Baseball in Japan. Japan and the World Economy, 8: 475-488.

Puro Yakyu Chosa Iin ni Okada Zenkantokura Sanshi, Daily Yomiuri (March 10).

Rottenberg, Simon. 1956. The Baseball Players' Labor Market. Journal of Political Economy, 64(June): $242-258$

Sasaki, Hiroya. 2011. Nenbo Chotei ni okeru 'Wakui no shori' no imi [The meaning of "Wakui's victory" in salary arbitration] http://sportsnews.blog.ocn.ne.jp/column/baseball110207_1_1.html (accessed February 7).

Scully, Gerald. 1974. Pay and Performance in Major League Baseball. American Economic Review, 64(December): 915-930.

Seymour, Harold. 1960. Baseball: The Early Years. New York: Oxford University Press.

Westbay, Michael. 2008. Pro Yakyu Database, http://www.japanesebaseball.com/data/indexProYakyu .jsp (accessed December 6, 2008).

Whiting, Robert. 1977. The Chrysanthemum and the Bat. Tokyo: Permanent Press. . 2004. The Meaning of Ichiro. New York: Warner Books.

.2010. Clandestine Campaign Led to Valentine's Demise, The Japan Times On-Line, http://search.japantimes.co.jp/cgi-bin/sb20100117j1.html (accessed January 17, 2010).

Zimbalist, Andrew. 1992a. Salaries and Performance: Beyond the Scully Model, in Diamonds are Forever: The Business of Baseball. edited by Paul M. Sommers, Washington, DC: Brookings Institute. 1992b. Baseball and Billions. New York: Basic Books.

"2010 Free Agents Etc". 2010. NPB Tracker, http://www.npbtracker.com/2010-free-agents-etc/ (accessed June 2, 2010). 